Article

\title{
Substantial Increase in Compliance with Saturated Fatty Acid Intake Recommendations after One Year Following the American Heart Association Diet
}

\author{
Miaomiao Zhao ${ }^{1,2}$, David Chiriboga ${ }^{3}$, Barbara Olendzki ${ }^{2}$, Bin Xie ${ }^{4}$, Yawen $\mathrm{Li}^{5}$, \\ Lisa Jo McGonigal ${ }^{6}$, Ana Maldonado-Contreras ${ }^{7}$ and Yunsheng Ma ${ }^{2, *}$ \\ 1 School of Clinical Medicine, Shanghai University of Medicine and Health Sciences, Shanghai 201318, China; \\ zhaomm@sumhs.edu.cn \\ 2 Division of Preventive and Behavioral Medicine, Department of Quantitative Health Sciences, \\ University of Massachusetts Medical School, Worcester, MA 01655, USA; \\ Barbara.Olendzki@umassmed.edu \\ 3 Division of Cardiovascular Medicine, Department of Medicine, University of Massachusetts Medical School, \\ Worcester, MA 01655, USA; David.Chiriboga@umassmed.edu \\ 4 School of Community \& Global Health, Claremont Graduate University, Claremont, CA 91711, USA; \\ bin.xie@cgu.edu \\ 5 School of Social Work, San Diego State University, San Diego, CA 92182, USA; yli@mail.sdsu.edu \\ 6 Department of Family Medicine and Community Health, University of Massachusetts Medical School, \\ Worcester, MA 01655, USA; LisaJo.McGonigal@umassmemorial.org \\ 7 Department of Microbiology \& Physiological Systems, University of Massachusetts Medical School, \\ Worcester, MA 01655, USA; Ana.Maldonado@umassmed.edu \\ * Correspondence: Yunsheng.Ma@umassmed.edu; Tel.: +1-508-856-1008
}

Received: 28 August 2018; Accepted: 4 October 2018; Published: 12 October 2018

\begin{abstract}
The American Heart Association (AHA) dietary guidelines recommend 30-35\% of energy intake (\%E) be from total fat, $<7 \% \mathrm{E}$ from saturated fatty acids (SFA), and $<1 \% \mathrm{E}$ from trans fatty acid (TFA). This study evaluates the effect of AHA dietary counselling on fat intake. Between 2009 and 2014, 119 obese adults with metabolic syndrome (MetS), (71\% women, average 52.5 years of age, and $34.9 \mathrm{~kg} / \mathrm{m}^{2}$ of body mass index), received individual and group counselling on the AHA diet, over a one-year study period. Each participant attended 2 individual sessions (months 1 and 12) and 12 group sessions, at one-month intervals. At baseline and one-year, we collected three random 24-h diet recalls (two weekdays and one weekend day). Fat intake patterns over time were analyzed using paired- $t$ test and linear mixed-effect models. There was significant variation on SFA and TFA intake per meal, being highest at dinner, in restaurants, and on weekends. Over the one-year study period, daily intake of total fat, SFA, and TFA decreased by $27 \%, 37 \%$ and $41 \%$, respectively ( $p$-value $<0.01$, each). Correspondingly, the percentage of participants complying with AHA's recommendations, increased from $25.2 \%$ to $40.2 \%$ for total fat ( $p$-value $=0.02$ ); from $2.5 \%$ to $20.7 \%$ for SFA ( $p$-value $<0.01$ ); and from $45.4 \%$ to $62 \%$ for TFA ( $p$-value $=0.02$ ). Additionally, SFA intake for all meal types at home decreased significantly ( $p$-value $<0.05$, each). AHA dietary counselling significantly increased the compliance with AHA dietary guidelines, with an eightfold increase in compliance in SFA intake. Nonetheless, $\sim 80 \%$ of our participants still exceeded the recommended SFA intake. Substantial efforts are needed to encourage low-SFA and low-TFA food preparation at home, with strong public health policies to decrease SFA and TFA in restaurants and prepared foods.
\end{abstract}

Keywords: fatty acids; metabolic syndrome; American Heart Association (AHA) diet 


\section{Introduction}

Cardiovascular disease (CVD) is the leading cause of death in the United States, and the risk is often exacerbated by a poor diet [1]. Saturated fatty acids (SFA) and trans fatty acids (TFA) have been widely understood to have a negative effect on serum cholesterol profiles, thereby increasing the risk of CVD [2-5]. Numerous randomized controlled trials [6-8] and prospective observational studies [9-12] have provided strong and consistent evidence that a decrease in dietary SFA reduces the risk of CVD events and all-cause mortality.

Worldwide guidelines have promoted the replacement of SFA with polyunsaturated fatty acids (PUFA), while suggesting that TFA intake should be entirely avoided. The current American Heart Association and American College of Cardiology (AHA/ACC) guidelines suggest a decrease in SFA intake to $5-6 \%$ of an individual's total daily energy intake (\%E) for those with elevated low-density lipoprotein cholesterol (LDL-C) concentration [13]. The 2015-2020 US Department of Agriculture Dietary Guidelines for Americans also recommends consuming $<10 \% \mathrm{E}$ from SFA for the general population, as well as the replacement of SFA with unsaturated fats [14]. Similarly, the National Lipid Association Expert Panel strongly recommends a healthy diet low in SFA ( $<7 \%$ E) [15]. However, despite these recommendations, SFA intake remains high in the United States [16].

Metabolic syndrome (MetS) is associated with an increased risk of developing CVD and Type 2 Diabetes Mellitus (T2DM) [17,18], and nearly 35\% of US adults and 50\% of those aged $\geq 60$ years suffer from MetS in 2011-2012 [19]. Epidemiological studies have demonstrated that higher SFA and TFA intake are modifiable dietary risk factors for MetS [20-23]. However, current SFA and TFA intake and meal-consumption patterns among MetS patients remain elusive. The purposes of AHA dietary recommendations are to promote a healthy diet and lifestyle, and since 1961 the AHA has suggested a reduction in dietary SFA and TFA in order to reduce the risk of CVD [13]. However, to our knowledge, there has been no research so far aimed at evaluating the effectiveness of dietary counselling, based on the AHA dietary guidelines, in decreasing SFA and TFA intake.

In this study, we investigated the effect of AHA-based dietary counselling on SFA and TFA intake among individuals with MetS. At the same time, we explored changes in SFA and TFA in different meal types, meal location, and day of the week. We hypothesized that the AHA dietary counselling would decrease SFA and TFA intake.

\section{Materials and Methods}

\subsection{Study Design and Participants}

Data of this investigation were from the "Can Do" study, which is a randomized controlled clinical trial (Clinical trial registration: NCT00911885). The purpose of the "Can Do" was to compare the multicomponent AHA dietary guidelines with a single-goal dietary suggestion to increase fiber intake for individuals with MetS. From May 2009 to February 2013, recruitment was conducted by the University of Massachusetts Medical School (UMMS), Worcester, MA. The detailed methodology was described previously [24]. In the "Can Do" study, a total of 240 subjects with MetS were randomized to one of two intervention groups: the AHA diet $(n=119)$ or the high-fiber diet $(n=121)$. Because of the focus of this investigation, we performed analyses using data only from the 119 subjects who participated in the AHA diet arm of the study. The study was conducted in accordance with the Declaration of Helsinki, and the protocol was approved by the Institutional Review Board (IRB) of UMMS. All subjects gave their informed consent for inclusion before they participated in the study. Adverse events during the study were reviewed by the study's Data Safety and Monitoring Board, and reported to the UMMS IRB.

Participants were eligible for the study if they: (1) were 21-70 years old; (2) had a body mass index (BMI) of 30-40 kg/m² and expressed interested in losing weight; (3) had MetS as defined by having any three of the five abnormal indicators [25]: waist circumference $>102 \mathrm{~cm}$ for men and $88 \mathrm{~cm}$ for women, triglycerides levels $\geq 150 \mathrm{mg} / \mathrm{dL}$, high-density lipoprotein cholesterol (HDL-C) levels $<40 \mathrm{mg} / \mathrm{dL}$ for 
men and $<50 \mathrm{mg} / \mathrm{dL}$ for women, hypertension with systolic blood pressure $\geq 130 \mathrm{mmHg}$ or diastolic blood pressure $\geq 85 \mathrm{mmHg}$, and fasting glucose concentrations $\geq 110 \mathrm{mg} / \mathrm{dL}$; (4) were non-smokers; (5) had access to a telephone; (6) were able to give informed consent; and (7) had approval to participate in the study from their primary care physician.

Exclusion criteria included: (1) diabetes diagnosis, or fasting blood sugar $\geq 120 \mathrm{mg} / \mathrm{dL}$; (2) acute coronary events within 6 months before the study; (3) a woman who was pregnant or lactating; (4) eating disorders; (5) bariatric surgery (6) current participation in a weight-loss program; (7) following other dietary regimens; (8) depression with a high risk of suicide; and (9) intention to move out central Massachusetts during the study period.

\subsection{American Heart Association Dietary Counselling}

Participants were instructed to follow the 2006 AHA dietary guidelines [26]: (1) choosing whole-grain, high-fiber foods ( $\geq 30 \mathrm{~g} /$ day of dietary fiber); (2) consuming lean animal and vegetable protein foods; (3) consuming vegetables and fruits; (4) eating fish at least twice a week; (5) reducing sugar intake; (6) minimizing sugary drinks; (7) reducing sodium intake; (8) no alcohol intake; (9) obtaining 50-55\%E from carbohydrate; (10) obtaining 15-20\%E from protein; (11) obtaining $30-35 \%$ from fat; (12) limiting saturated fat to $<7 \% \mathrm{E}$ and trans fat to $<1 \% \mathrm{E}$; and (13) limiting dietary cholesterol intake to $<300 \mathrm{mg} /$ day. Each participant was encouraged to attend 2 individual sessions and 12 group sessions during the one-year study period [27]. Details of the individual and group sessions are displayed in Table 1. Each session was audio-recorded, and a random 10\% were selected for counselling fidelity review by an auditor.

Table 1. American Heart Association (AHA) dietary intervention in the clinical study.

\begin{tabular}{cc}
\hline Month/Session & Topic \\
\hline Month 1/group 1 & Orientation/Getting Started with AHA Eating \\
Month 1/individual visit \#1 & Individual Consultation \\
Month 2/group 2 & Hunger, Satiety, and Appetite \\
Month 3/group 3 & AHA Meal Planning: Focus on Whole Grains \\
Month 3/group 4 & AHA Meal Planning: Focus on Proteins \\
Month 4/group 5 & AHA Meal Planning: Focus on Vegetables \\
Month 5/group 6 & AHA Meal Planning: Focus on Fats and Oils \\
Month 6/group 7 & AHA Meal Planning: Focus on Fruits \\
Month 7/group 8 & Four keys to AHA Eating Out \\
Month 8/group 9 & The Science of Taste \\
Month 9/group 10 & Motivation and Long-Term Changes \\
Month 10/group 11 & How to Improve Dietary Quality \\
Month 11/group 12 & Savvy Super Marketing: Supermarket Tour \\
Month 12/individual visit \#2 & Individual Consultation \\
\hline
\end{tabular}

\subsection{Dietary Assessment}

Three 24-h dietary recalls (two on weekdays and once on weekend) were performed at both baseline and one-year visits in order to determine the average individual dietary intake (within three weeks of the study visit). Dietary recalls were performed by dietitians who were blinded to the intervention process. Participants were provided with a booklet detailing food portions to estimate portion size prior to the call. Data for SFA, TFA, other selected fatty acids (FA), total energy, and other nutrients were calculated using the Nutritional Data System for Research (NDS-R, 2010-2012, Minneapolis, MN, USA) [28].

\subsection{Statistical Analyses}

Continuous variables were summarized as means ( $95 \%$ confidence interval (CI)), and the comparison between groups was based on student's $t$-test or analysis of variance (ANOVA); 
categorical variables were presented as percentage and the comparison between groups were based on chi-squared test. Paired- $t$ test was conducted to examine SFA, TFA, and other selected FA intake patterns over time. Linear mixed-effect models were conducted to examine the differences of SFA and TFA intake between baseline and one-year visits, meal type, meal location and meal time, with time point set as a fixed effect and participant identification as a random effect. For analyses of meal location, independent variables included time point, meal type, gender, meal location and the interaction of time point, meal type and meal location. Meanwhile, meal time was assessed, with independent variables that included time point, meal type, gender, meal time and the interaction of time point, meal type and meal time. The \%E of SFA and TFA were also analyzed after adjusting for total energy intake. All analyses were conducted using SAS 9.4 (SAS Institute, Cary, NC, USA). Two-side $p$ values less than 0.05 indicated statistical significance.

\section{Results}

The present investigation included 119 obese subjects with MetS (BMI: $34.9 \mathrm{~kg} / \mathrm{m}^{2}$, 95\% CI 34.4 to 35.5). The average age was 52.5 years old (95\% CI 50.7 to 54.3 years), and 85 of the 119 participants (71\%) were women. Mean attendance to AHA dietary counselling was 7.9 sessions (standard deviation (SD) = 3.9) out of a total of 14 sessions. Baseline SFA and TFA intake by demographic characteristics are presented in Table 2. SFA intake was significantly higher in males ( $p$-value $=0.001$ for $\mathrm{g} /$ day) and among Caucasians ( $p$-value $=0.038$ and $p$-value $=0.020$ for $\mathrm{g} /$ day and $\% \mathrm{E}$ ). TFA intake was significantly higher in those with lower household income ( $p$-value $=0.028$ for $g / d a y)$. During the one-year study, a total of four adverse events were reported. It was determined that the causes of these adverse events were not treatment-related (hysterectomy, pneumonia, lung cancer, and kidney stones).

Figure 1 illustrates the improvement in compliance, between the baseline and the one-year study visit, with the AHA recommendations for total fat, SFA, and TFA intake among study participants. After one-year dietary counselling, percentage of participants who were compliant with the AHA dietary guidelines fat intake recommendations as $\% \mathrm{E}$ increased from $25.2 \%$ to $40.2 \%$ for total fat intake ( $p$-value $=0.02$ ); from $2.5 \%$ to $20.7 \%$ ( $p$-value $<0.01)$ for SFA intake; and from $45.4 \%$ to $62 \%$ $(p$-value $=0.02)$ for TFA intake.

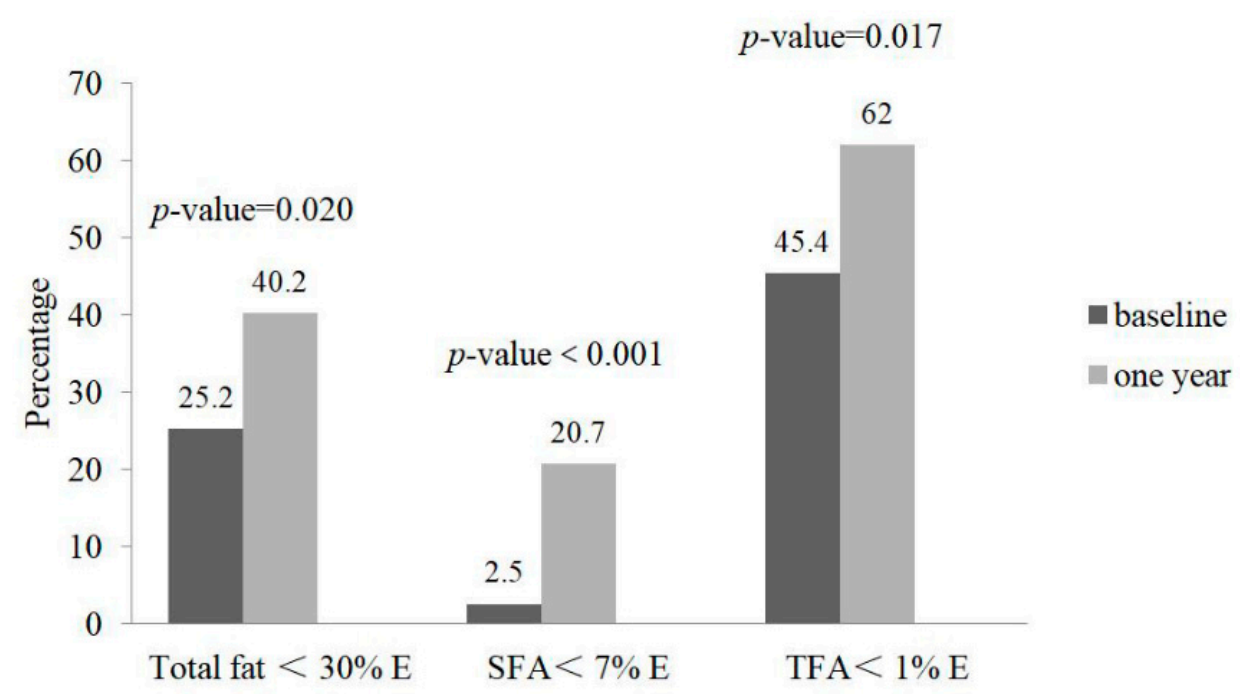

Figure 1. Percentage of participants complying with the AHA dietary intake recommendations for total fat, saturated fatty acid (SFA) and trans fatty acid (TFA) over time. 
Table 2. Daily Saturated Fatty Acids (SFA) and Trans Fatty Acids (TFA) intake at baseline by participants' demographic characteristics.

\begin{tabular}{|c|c|c|c|c|c|c|c|c|c|}
\hline \multirow{2}{*}{ Variable } & \multirow{2}{*}{$n(\%)$} & \multicolumn{4}{|c|}{ SFA Intake } & \multicolumn{4}{|c|}{ TFA Intake } \\
\hline & & g/day & $p$-Value & $\% \mathrm{E}$ & $p$-Value & g/day & $p$-Value & $\% \mathrm{E}$ & $p$-Value \\
\hline \multicolumn{10}{|l|}{ Gender } \\
\hline Male & $34(28.6)$ & 32.18 (26.35 to 38.00$)$ & 0.001 & 11.86 (10.77 to 12.94$)$ & 0.471 & $3.14(2.37$ to 3.91$)$ & 0.078 & 1.13 (0.98 to 1.28$)$ & 0.524 \\
\hline Female & 85 (71.4) & 24.09 (21.97 to 26.21$)$ & & 11.44 (10.86 to 12.02$)$ & & 2.50 (2.17 to 2.84$)$ & & 1.20 (1.07 to 1.34$)$ & \\
\hline \multicolumn{10}{|l|}{ Age group } \\
\hline $20-40$ & $12(10.1)$ & 32.87 (26.01 to 39.74 ) & 0.296 & 11.28 (9.88 to 12.68$)$ & 0.771 & 3.41 (1.78 to 5.03$)$ & 0.24 & 1.08 (0.78 to 1.37$)$ & 0.424 \\
\hline $41-60$ & 35 (29.4) & 24.91 (21.59 to 28.24$)$ & & 11.20 (10.31 to 12.09 ) & & 2.44 (2.01 to 2.86$)$ & & 1.14 (0.94 to 1.35$)$ & \\
\hline $51-60$ & $46(38.7)$ & 26.26 (21.62 to 30.90$)$ & & 11.81 (10.87 to 12.74$)$ & & 2.89 (2.25 to 3.52$)$ & & $1.29(1.10$ to 1.48$)$ & \\
\hline 61-70 & $26(21.8)$ & 25.66 (21.34 to 29.97$)$ & & 11.74 (10.62 to 12.86$)$ & & $2.33(1.86$ to 2.81$)$ & & $1.09(0.90$ to 1.28$)$ & \\
\hline \multicolumn{10}{|l|}{ Race/ethnicity } \\
\hline Caucasian & $108(90.8)$ & 27.17 (24.74 to 29.59$)$ & 0.038 & 11.75 (11.21 to 12.29$)$ & 0.020 & 2.73 (2.39 to 3.06$)$ & 0.406 & $1.20(1.08$ to 1.31$)$ & 0.380 \\
\hline Others & $11(9.2)$ & 18.86 (12.57 to 25.16$)$ & & 9.69 (8.36 to 11.02$)$ & & $2.26(0.84$ to 3.68$)$ & & $1.03(0.74$ to 1.33$)$ & \\
\hline \multicolumn{10}{|l|}{ Highest education level } \\
\hline High school diploma or less & $13(11.0)$ & 30.98 (20.35 to 41.62$)$ & 0.335 & 12.47 (10.67 to 14.28$)$ & 0.48 & 2.59 (1.36 to 3.82$)$ & 0.873 & $1.08(0.72$ to 1.43$)$ & 0.777 \\
\hline Bachelor's degree or less & $71(60.2)$ & 26.23 (23.46 to 29.00$)$ & & 11.49 (10.87 to 12.11$)$ & & 2.75 (2.35 to 3.16$)$ & & 1.19 (1.06 to 1.32$)$ & \\
\hline Graduate/professional & $34(28.8)$ & 24.86 (20.48 to 29.25$)$ & & 11.43 (10.34 to 12.52$)$ & & 2.57 (1.92 to 3.23$)$ & & 1.21 (0.98 to 1.44$)$ & \\
\hline \multicolumn{10}{|l|}{ Household income } \\
\hline$\$ 0-\$ 30,000$ & $12(10.1)$ & 33.45 (22.53 to 44.37$)$ & 0.177 & 11.67 (9.48 to 13.87 ) & 0.385 & 4.21 (2.08 to 6.33$)$ & 0.028 & 1.32 (0.93 to 1.72$)$ & 0.447 \\
\hline$\$ 30,000-\$ 50,000$ & $19(16.0)$ & 26.60 (21.42 to 31.78$)$ & & 12.34 (10.98 to 13.71$)$ & & 2.72 (1.99 to 3.45$)$ & & 1.35 (0.93 to 1.76$)$ & \\
\hline$\$ 50,000-\$ 75,000$ & $20(16.8)$ & 25.14 (17.08 to 33.20$)$ & & 11.31 (9.63 to 12.99$)$ & & 2.46 (1.96 to 2.95$)$ & & 1.18 (1.01 to 1.36$)$ & \\
\hline More than $\$ 75,000$ & $43(36.1)$ & 27.13 (23.85 to 30.42$)$ & & 11.79 (11.03 to 12.55$)$ & & 2.61 (2.16 to 3.06$)$ & & 1.14 (0.98 to 1.30$)$ & \\
\hline Unclear & $25(21.0)$ & 22.61 (18.73 to 26.50$)$ & & 10.72 (9.80 to 11.65$)$ & & 2.25 (1.56 to 2.94$)$ & & $1.05(0.85$ to 1.26$)$ & \\
\hline \multicolumn{10}{|l|}{ Components of MetS } \\
\hline 3 & $58(48.7)$ & 24.37 (21.49 to 27.25$)$ & 0.03 & 11.26 (10.47 to 12.06$)$ & 0.532 & 2.61 (2.14 to 3.08$)$ & 0.497 & 1.20 (1.04 to 1.35$)$ & 0.783 \\
\hline 4 & $41(34.5)$ & 30.59 (25.62 to 35.57$)$ & & 11.82 (11.02 to 12.62$)$ & & 2.93 (2.31 to 3.55$)$ & & 1.13 (1.00 to 1.27$)$ & \\
\hline 5 & $20(16.8)$ & 23.69 (20.31 to 27.08$)$ & & 11.90 (10.61 to 13.18$)$ & & 2.40 (1.76 to 3.03$)$ & & 1.24 (0.87 to 1.60$)$ & \\
\hline
\end{tabular}

MetS, metabolic syndrome. 
The comparison of selected daily fat intake (both $\mathrm{g}$ and \%E) between baseline and one-year follow-up visit are presented in Table 3. Average intake of total fat, SFA and TFA decreased from $74.8 \mathrm{~g} /$ day, $26.4 \mathrm{~g} /$ day and $2.7 \mathrm{~g} /$ day at baseline to $54.4 \mathrm{~g} /$ day, $16.7 \mathrm{~g} /$ day and $1.6 \mathrm{~g} /$ day at one-year (all $p$-values < 0.01 ); and the corresponding $\% \mathrm{E}$ decreased from $33.1 \%, 11.6 \%$ and $1.2 \%$ to $31.1 \%$, $9.7 \%$ and $0.9 \%$ (all $p$-values $<0.01$ ). Intake as $\mathrm{g} /$ day of total monounsaturated fatty acid (MUFA), oleic acid, total PUFA, linoleic acid (LA), and alpha linolenic acid (ALA) decreased significantly over the one-year period (all $p$-values $<0.05$ ); however, their intakes as \%E did not decrease. Only the intake as $\% \mathrm{E}$ of arachidonic acid (AA) decreased significantly ( $p$-value $=0.021)$. Meanwhile, total energy intake decreased significantly after the one-year AHA counselling ( $p$-value $<0.01$ ).

Table 3. Comparison of intakes of selected fatty acids between baseline and one year.

\begin{tabular}{|c|c|c|c|c|}
\hline & Baseline $(n=119)$ & One Year $(n=92)$ & Change $(n=92)$ & \multirow{2}{*}{$p$-Value } \\
\hline & Mean $(95 \%$ CI $)$ & Mean $(95 \% \mathrm{CI})$ & Mean $(95 \%$ CI) & \\
\hline Total energy (kcal/day) & 1957.7 (1829.1 to 2086.3 ) & $1500.9(1386.8$ to 1615.0$)$ & $-489.4(-604.30$ to -374.50$)$ & $<0.001$ \\
\hline \multicolumn{5}{|l|}{ Total Fat } \\
\hline g/day & $74.76(68.95$ to 80.58$)$ & 54.36 (48.89 to 59.83$)$ & $-21.95(-27.50$ to -16.39$)$ & $<0.001$ \\
\hline$\% \mathrm{E}$ & 33.08 (32.06 to 34.09 ) & $31.06(29.45$ to 32.68$)$ & $-2.15(-3.74$ to -0.56$)$ & 0.009 \\
\hline \multicolumn{5}{|l|}{ SFA, total } \\
\hline g/day & $26.40(24.10$ to 28.70$)$ & $16.69(15.00$ to 18.38$)$ & $-10.51(-12.95$ to -8.08$)$ & $<0.001$ \\
\hline$\% \mathrm{E}$ & $11.56(11.05$ to 12.07$)$ & $9.67(8.99$ to 10.34$)$ & $-2.06(-2.84$ to -1.29$)$ & $<0.001$ \\
\hline \multicolumn{5}{|l|}{ TFA, total } \\
\hline g/day & 2.69 (2.36 to 3.01$)$ & $1.58(1.32$ to 1.84$)$ & $-1.19(-1.59$ to -0.80$)$ & $<0.001$ \\
\hline$\% \mathrm{E}$ & 1.18 (1.08 to 1.29$)$ & $0.89(0.79$ to 1.00$)$ & $-0.32(-0.47$ to -0.16$)$ & $<0.001$ \\
\hline \multicolumn{5}{|l|}{ MUFA, total } \\
\hline g/day & 26.30 (24.29 to 28.30$)$ & 19.88 (17.75 to 22.01$)$ & $-7.01(-8.96$ to -5.07$)$ & $<0.001$ \\
\hline$\% \mathrm{E}$ & 11.77 (11.29 to 12.24$)$ & 11.35 (10.61 to 12.08$)$ & $-0.50(-1.22$ to 0.22$)$ & 0.17 \\
\hline \multicolumn{5}{|l|}{ Oleic acid } \\
\hline g/day & 24.52 (22.61 to 26.43 ) & 18.63 (16.59 to 20.67 ) & $-6.49(-8.35$ to -4.64$)$ & $<0.001$ \\
\hline$\% \mathrm{E}$ & $11.28(10.76$ to 11.81$)$ & 10.98 (10.25 to 11.72$)$ & $-0.41(-1.13$ to 0.31$)$ & 0.259 \\
\hline \multicolumn{5}{|l|}{ PUFA, total } \\
\hline g/day & $16.01(14.40$ to 17.62$)$ & 13.15 (11.41 to 14.88$)$ & $-2.90(-4.53$ to -1.27$)$ & 0.001 \\
\hline$\% \mathrm{E}$ & $7.05(6.63$ to 7.48$)$ & $7.34(6.73$ to 7.94$)$ & $0.39(-0.27$ to 1.05$)$ & 0.245 \\
\hline \multicolumn{5}{|c|}{ 年 } \\
\hline g/day & 14.05 (12.58 to 15.53$)$ & 11.50 (9.89 to 13.12$)$ & $-2.62(-4.12$ to -1.13$)$ & 0.001 \\
\hline$\% \mathrm{E}$ & $6.32(5.92$ to 6.71$)$ & $6.70(6.10$ to 7.30$)$ & $0.40(-0.24$ to 1.03$)$ & 0.216 \\
\hline \multicolumn{5}{|l|}{ ALA } \\
\hline g/day & 1.52 (1.36 to 1.67$)$ & $1.26(1.10$ to 1.41$)$ & $-0.26(-0.46$ to -0.05$)$ & 0.014 \\
\hline$\% \mathrm{E}$ & $0.70(0.64$ to 0.76$)$ & $0.76(0.69$ to 0.83$)$ & $0.06(-0.04$ to 0.17$)$ & 0.22 \\
\hline \multicolumn{5}{|l|}{ AA } \\
\hline g/day & $0.13(0.12$ to 0.15$)$ & $0.11(0.10$ to 013$)$ & $-0.01(-0.03$ to 0.01$)$ & 0.308 \\
\hline$\% \mathrm{E}$ & $0.06(0.06$ to 0.07$)$ & $0.07(0.06$ to 0.08$)$ & $0.01(0.00$ to 0.02$)$ & 0.021 \\
\hline \multicolumn{5}{|l|}{ EPA } \\
\hline g/day & 0.05 (0.03 to 0.07$)$ & 0.05 (0.03 to 0.07$)$ & $0.00(-0.02$ to 0.02$)$ & 0.774 \\
\hline \multicolumn{5}{|l|}{ DPA } \\
\hline g/day & 0.03 (0.02 to 0.04$)$ & 0.02 (0.02 to 0.03$)$ & $0.00(-0.01$ to 0.01$)$ & 0.855 \\
\hline \multicolumn{5}{|l|}{ DHA } \\
\hline g/day & 0.12 (0.08 to 0.17$)$ & $0.12(0.08$ to 0.17$)$ & $0.01(-0.03$ to 0.06$)$ & 0.559 \\
\hline
\end{tabular}

SFA, saturated fatty acid; TFA, trans fatty acid; MUFA, monounsaturated fatty acid; PUFA, polyunsaturated fatty acid; LA, linoleic acid; ALA, alpha linolenic acid; AA, arachidonic acid; EPA, eicosapentaenoic acid; DPA, docosapentaenoic acid; DHA, docosahexaenoic acid. The paired- $t$ test was used to examine if the difference between baseline and one-year is equal to zero.

Tables 4 and 5 demonstrate the SFA and TFA intake by meal type, location, and day of week. Overall, for SFA, subjects consumed less when they ate at home with significant one-year differences in intake observed at breakfast (from $4.54 \mathrm{~g}$ to $2.48 \mathrm{~g}$, $p$-value $<0.05$ ), lunch (from $7.53 \mathrm{~g}$ to $5.13 \mathrm{~g}$, $p$-value $<0.05$ ), dinner (from $10.05 \mathrm{~g}$ to $6.51 \mathrm{~g}, p$-value $<0.05$ ), and snack (from $4.03 \mathrm{~g}$ to $2.09 \mathrm{~g}$, $p$-value $<0.05)$. Subjects also consumed significantly less at lunch at one year when they ate in a restaurant or fast food outlet (from $10.24 \mathrm{~g}$ to $6.53 \mathrm{~g}$, $p$-value < 0.05 ). At the same time, SFA intake from weekday breakfast, dinner, and snacks and weekend lunch, dinner, and snacks decreased significantly from baseline to one-year (all $p$-values $<0.05$ ). However, significant decrease of SFA intake as \%E was only observed with snacks consumed at home (from $10.37 \%$ to $7.95 \%, p$-value $<0.05$ ) and away from home (from $11.13 \%$ to $7.06 \%$, $p$-value $<0.05$ ) after the one-year counselling. 
Compared to baseline, TFA intake after the one-year counselling decreased when subjects ate at home, with significant differences observed for dinner (from $0.90 \mathrm{~g}$ to $0.60 \mathrm{~g}, p$-value $<0.05$ ) and snacks (from $0.42 \mathrm{~g}$ to $0.17 \mathrm{~g}, p$-value $<0.05$ ). For meals consumed in a restaurant/fast food chain, TFA intake during lunch decreased significantly at one year (from $1.81 \mathrm{~g}$ to $0.95 \mathrm{~g}$, $p$-value $<0.05$ ). At the same time, TFA intake from lunch in weekend days decreased significantly from baseline to one-year (from $1.12 \mathrm{~g}$ to $0.52 \mathrm{~g}, p$-value $<0.05$ ). TFA intake as $\% \mathrm{E}$ from different meal locations and days of week between baseline and one-year visit were similar. 
Table 4. SFA intake by meal type, weekday and location at baseline and one year.

\begin{tabular}{|c|c|c|c|c|c|c|c|c|}
\hline \multirow{2}{*}{ Location } & \multicolumn{2}{|c|}{ Breakfast } & \multicolumn{2}{|c|}{ Lunch } & \multicolumn{2}{|c|}{ Dinner } & \multicolumn{2}{|c|}{ Snack } \\
\hline & Baseline & One-Year & Baseline & One-Year & Baseline & One-Year & Baseline & One-Year \\
\hline \multicolumn{9}{|l|}{ At home } \\
\hline & $n=123$ & $n=146$ & $n=93$ & $n=91$ & $n=194$ & $n=176$ & $n=346$ & $n=262$ \\
\hline SFA (g) & $4.54(3.49-5.59)^{2}$ & $2.48(1.50-3.45)^{1,2}$ & $7.53(6.35-8.72)^{2}$ & $5.13(3.93-6.33)^{1}$ & $10.05(9.19-10.91)$ & $6.51(5.61-7.41)^{1}$ & $4.03(3.33-4.73)^{2}$ & $2.09(1.31-2.87)^{1,2}$ \\
\hline SFA (\%E) & $9.63(7.97-11.28)$ & $7.68(6.14-9.21)$ & $11.25(9.36-13.13)$ & $9.80(7.91-11.69)$ & $10.45(9.03-11.87)$ & $9.43(8.00-10.86)$ & $10.37(9.28-11.46)$ & $7.95(6.72-9.19)^{1}$ \\
\hline \multicolumn{9}{|c|}{ Away from home } \\
\hline & $n=30$ & $n=24$ & $n=55$ & $n=64$ & $n=7$ & $n=10$ & $n=131$ & $n=109$ \\
\hline SFA (g) & $4.82(2.80-6.84)$ & $3.64(1.38-5.89)$ & $6.11(4.60-7.62)$ & $4.35(2.94-5.76)$ & $7.99(3.88-12.11)$ & $5.38(1.93-8.83)$ & $2.83(1.80-3.86)^{2}$ & $1.54(0.42-2.67)^{2}$ \\
\hline SFA (\%E) & $11.03(7.83-14.23)$ & $10.21(6.62-13.79)$ & $8.54(6.14-10.93)$ & $7.61(5.38-9.84)$ & $8.67(2.11-15.22)$ & $8.63(3.14-14.13)$ & $11.13(9.50-12.76)$ & $7.06(5.27-8.86)^{1}$ \\
\hline \multicolumn{9}{|c|}{ Restaurant/fast food } \\
\hline & $n=15$ & $n=5$ & $n=33$ & $n=23$ & $n=37$ & $n=24$ & $n=21$ & $n=4$ \\
\hline SFA (g) & $8.81(5.98-11.63)^{3}$ & $9.90(5.05-14.76)^{3}$ & $10.24(8.31-12.16)^{3}$ & $6.53(4.21-8.84)^{1,2}$ & $11.63(9.80-13.45)$ & $10.60(8.36-12.85)^{3}$ & $5.83(3.41-8.25)^{2}$ & $5.62(0.20-11.04)$ \\
\hline SFA (\%E) & $12.75(8.25-17.24)$ & $11.18(3.45-18.91)$ & $9.09(5.99-12.18)$ & $9.55(5.87-13.24)$ & $9.11(6.13-12.08)$ & $8.88(5.26-12.49)$ & $13.72(9.88-17.56)$ & $14.41(5.78-23.04)$ \\
\hline \multicolumn{9}{|l|}{ Weekdays } \\
\hline & $n=102$ & $n=124$ & $n=115$ & $n=123$ & $n=148$ & $n=144$ & $n=332$ & $n=266$ \\
\hline SFA (g) & $4.63(3.49-5.76)^{2}$ & $2.58(1.54-3.62)^{1,2}$ & $6.46(5.38-7.53)^{2}$ & $5.08(4.03-6.12)^{2}$ & $9.33(8.38-10.29)$ & $7.00(6.03-7.98)^{1}$ & $3.34(2.64-4.05)^{2}$ & $2.09(1.32-2.86)^{1,2}$ \\
\hline SFA (\%E) & $9.73(7.94-11.52)$ & $7.43(5.79-9.07)^{2}$ & $9.48(7.78-11.18)$ & $9.16(7.51-10.80)$ & $10.01(8.44-11.57)$ & $9.70(8.14-11.25)$ & $11.08(9.97-12.19)$ & $7.50(6.27-8.73)^{2}$ \\
\hline \multicolumn{9}{|c|}{ Weekend days } \\
\hline & $n=66$ & $n=51$ & $n=66$ & $n=55$ & $n=90$ & $n=66$ & $n=166$ & $n=109$ \\
\hline SFA (g) & $5.58(4.20-6.95)^{2}$ & $3.78(2.22-5.33)^{2}$ & $9.64(8.26-11.02)^{2,4}$ & $5.18(3.68-6.68)^{1}$ & $11.73(10.54-12.92)^{4}$ & $6.91(5.53-8.29)^{1}$ & $4.71(3.80-5.63)^{2,4}$ & $1.87(0.75-2.98)^{1,2}$ \\
\hline SFA (\%E) & $10.83(8.66-13.01)$ & $9.91(7.45-12.38)$ & $11.02(8.80-13.23)$ & $8.66(6.28-11.05)$ & $10.49(8.52-12.46)$ & $8.56(6.36-10.76)$ & $10.04(8.60-11.49)$ & $8.52(6.75-10.28)$ \\
\hline
\end{tabular}


Table 5. TFA intake by meal type, weekday and location at baseline and one year.

\begin{tabular}{|c|c|c|c|c|c|c|c|c|}
\hline \multirow{2}{*}{ Location } & \multicolumn{2}{|c|}{ Breakfast } & \multicolumn{2}{|c|}{ Lunch } & \multicolumn{2}{|c|}{ Dinner } & \multicolumn{2}{|c|}{ Snack } \\
\hline & Baseline & One-Year & Baseline & One-Year & Baseline & One-Year & Baseline & One-Year \\
\hline \multicolumn{9}{|l|}{ At home } \\
\hline & $n=123$ & $n=146$ & $n=93$ & $n=91$ & $n=194$ & $n=176$ & $n=346$ & $n=262$ \\
\hline TFA (g) & $0.36(0.17-0.56)^{2}$ & $0.21(0.03-0.39)^{2}$ & $0.68(0.46-0.90)$ & $0.38(0.16-0.61)$ & $0.90(0.75-1.06)$ & $0.60(0.43-0.76)^{1}$ & $0.42(0.30-0.54)^{2}$ & $0.17(0.03-0.30)^{1,2}$ \\
\hline TFA $(\% \mathrm{E})$ & $0.79(0.54-1.05)$ & $0.68(0.45-0.92)$ & $1.09(0.80-1.38)$ & $0.81(0.51-1.10)$ & $0.83(0.61-1.05)$ & $0.80(0.58-1.02)$ & $0.95(0.78-1.12)$ & $0.94(0.75-1.13)$ \\
\hline \multicolumn{9}{|c|}{ Away from home } \\
\hline & $n=30$ & $n=24$ & $n=55$ & $n=64$ & $n=7$ & $n=10$ & $n=131$ & $n=109$ \\
\hline TFA (g) & $0.40(0.01-0.78)$ & $0.47(0.04-0.90)$ & $0.84(0.55-1.12)$ & $0.52(0.26-0.79)$ & $1.10(0.31-1.90)$ & $0.36(-0.30-1.03)$ & $0.32(0.13-0.51)$ & $0.11(-0.10-0.32)$ \\
\hline TFA (\%E) & $0.90(0.40-1.40)$ & $1.15(0.60-1.71)$ & $1.00(0.63-1.37)$ & $0.78(0.43-1.12)$ & $1.04(0.02-2.06)$ & $0.43(-0.43-1.29)$ & $0.96(0.70-1.22)$ & $0.64(0.34-0.94)$ \\
\hline \multicolumn{9}{|c|}{ Restaurant/ fast food } \\
\hline & $n=15$ & $n=5$ & $n=33$ & $n=23$ & $n=37$ & $n=24$ & $n=21$ & $n=4$ \\
\hline TFA (g) & $1.12(0.58-1.66)^{3}$ & $1.61(0.67-2.54)^{3}$ & $1.81(1.45-2.18)^{3}$ & $0.95(0.51-1.39)^{1,2,3}$ & $1.47(1.12-1.81)^{3}$ & $2.10(1.67-2.53)^{3}$ & $0.60(0.14-1.06)^{2}$ & $1.51(0.46-2.55)^{3}$ \\
\hline TFA (\%E) & $1.64(0.94-2.34)^{3}$ & $1.87(0.66-3.08)$ & $1.97(1.49-2.45)^{2,3}$ & $1.21(0.64-1.78)$ & $1.18(0.72-1.64)$ & $1.62(1.06-2.19)^{3}$ & $1.38(0.79-1.98)$ & $1.55(0.20-2.90)$ \\
\hline \multicolumn{9}{|l|}{ Weekdays } \\
\hline & $n=102$ & $n=124$ & $n=115$ & $n=123$ & $n=148$ & $n=144$ & $n=332$ & $n=266$ \\
\hline TFA (g) & $0.42(0.20-0.63)^{2}$ & $0.26(0.07-0.46)^{2}$ & $0.84(0.63-1.04)$ & $0.52(0.32-0.71)$ & $0.97(0.79-1.15)$ & $0.76(0.57-0.94)$ & $0.36(0.24-0.49)^{2}$ & $0.17(0.03-0.31)^{2}$ \\
\hline & $0.90(0.62-1.18)$ & $0.73(0.47-0.98)$ & $1.18(0.92-1.44)$ & $0.91(0.66-1.17)$ & $0.89(0.65-1.13)$ & $0.86(0.62-1.10)$ & $0.94(0.76-1.11)$ & $0.74(0.54-0.93)$ \\
\hline \multicolumn{9}{|c|}{ Weekend days } \\
\hline & $n=66$ & $n=51$ & $n=66$ & $n=55$ & $n=90$ & $n=66$ & $n=166$ & $n=109$ \\
\hline TFA (g) & $0.48(0.21-0.74)^{2}$ & $0.38(0.08-0.68)^{2}$ & $1.12(0.85-1.38)$ & $0.52(0.23-0.81)^{1}$ & $1.05(0.82-1.28)$ & $0.78(0.52-1.05)$ & $0.49(0.32-0.66)^{2}$ & $0.19(-0.02-0.39)^{2}$ \\
\hline TFA (\%E) & $0.88(0.54-1.22)$ & $0.96(0.58-1.35)$ & $1.25(0.91-1.60)^{2}$ & $0.72(0.35-1.09)$ & $0.80(0.50-1.11)$ & $0.88(0.54-1.22)$ & $1.09(0.86-1.32)$ & $1.25(0.97-1.54)^{4}$ \\
\hline
\end{tabular}

All values are means $(95 \%$ CI). TFA intakes per meal and TFA as a percentage of total energy by meal were estimated by LSMEANS of PROC MIXED model in SAS. $n$ : The average number of times during the three $24 \mathrm{~h}$ given at the study point that participants ate the corresponding meal at the given location/day. "At home"-meals were eaten at home; "Away from home" - meals were eaten at work, school, friend's home, party, or reception; "Restaurant/fast food" - meals were eaten at a restaurant, cafeteria, fast food chains, take-out, or store. ${ }^{1} p$-value $<0.05$ and $p$ values compared differences between baseline and 1 year. ${ }^{2} p$-value $<0.05$ and $p$ values compared differences to dinner at the same time point. ${ }^{3} p$-value $<0.05$ and $p$ values compared differences between restaurant/fast food and eaten at home at the same time point. ${ }^{4} p$-value $<0.05$ and $p$ values compared differences to weekdays. 


\section{Discussion}

The present study indicates that the proportion of participants complying with the AHA dietary guidelines for intake of total fat, SFA, and TFA significantly increased after the one-year AHA dietary intervention, by $60 \%, 800 \%$ and $36 \%$, respectively. Correspondingly, significant decreases were observed for daily intake of total fat, SFA, and TFA (both in g/day and as \%E). Additionally, SFA intake for all meal types at home decreased significantly. Nevertheless, the SFA intake from a large proportion $(79.3 \%)$ of participants still exceeded recommended limits.

Dietary SFA intake is not only associated with risk of CVD, but also negatively affects bone mineral density [29] and cancer [30-34]. Foods containing a high proportion of saturated fat include animal products such as cream, cheese, butter, other whole milk dairy products and fatty meats. Certain vegetable products also have high saturated fat content, such as coconut oil and palm kernel oil. Many prepared foods are high in saturated fat content as well, such as pizza, dairy desserts, and sausage. While not all SFA are metabolized the same, detrimental effects of diets rich in total SFA have been widely recognized, and national nutritional guidelines have emphasized the need to replace SFA intakes with unsaturated fats. The implementation strategy currently recommended to achieve the reduction of dietary SFA is to shift from food choices high in saturated fat to those high in polyunsaturated and monounsaturated fats $[13,14]$. However, this is not only about a better choice of oils, but about shifting away from some foods to others that may be quite different in taste, texture, and overall dietary pattern. To achieve meaningful SFA reductions, the country requires strong public health policies providing information on SFA content alerting customers to improve their food choices; in addition to consumer education and agreements with food producers to limit the use of SFA.

Dietary TFA can be naturally derived from ruminant-based meat and dairy products, or artificially through partially hydrogenated oils (PHOs) in the food industry and manufacturing processes [35]. By the late 1990s in the United States, most TFA in the diet (79\%) came from PHOs [36]. In our study, the biggest contributors of TFA were meat, poultry, and fish recipes $(12.47 \%$ at baseline vs. $18.75 \%$ at one year), followed by breads, rolls, biscuits, and other related products $(10.75 \%$ at baseline vs. $10.70 \%$ at one year) (data not shown in table). In the United States, nutritional labelling of TFA content became mandatory in 2006 [37]. In 2007, New York City (NYC) became the first in the United States to pass a regulatory restriction on PHO use, targeting restaurants. In June 2015, the US Food and Drug Administration (FDA) announced that PHO use in foods would be phased out of the US market by June 2018, as they were not considered safe for consumption [38], although companies have now been granted an extension to January 2020 [39]. Our study showed that the percentage of participants who complied with AHA dietary recommendations, the daily intake of TFA (both g/day and \%E), and TFA intake for dinner and snacks at home, have all improved after the one-year AHA dietary counselling. Education to encourage consumers to further change their dietary patterns and increase healthy cooking at home are needed, and the FDA recommendations to restrict the use of industrially produced TFA in restaurants should be strictly enforced.

PUFAs have usually been shown to be associated with beneficial health effects on CVD. Omega-3 PUFAs have been demonstrated to decrease the production of inflammatory mediators, having a positive effect in obesity, diabetes, and MetS. Moreover, they significantly decrease the appearance of CVD risk factors [40-42]. As for MUFAs, cumulative evidence indicates that dietary MUFAs prevent or ameliorate MetS and CVD risk by favorably modulating blood lipids, blood pressure and insulin sensitivity [43-45]. Moreover, the majority of epidemiological data favor the cardioprotective activity of dietary MUFAs [43,46]. In the present study, we found that intake in grams of MUFA, oleic acid, total PUFA, LA, ALA significantly decreased after the one-year counselling; however, their intake as \%E did not decrease. Only the intake as \%E of AA decreased significantly. Therefore, the significant decrease as g/day may be a result of reduced total energy intake. The AHA dietary counselling in our study was based on the 2006 AHA guidelines, which did not include replacing SFA with PUFA, as recommended in the present AHA guideline [47]. Therefore, we did not observe significant change of unsaturated FAs, except AA, after the one-year counselling. 
One of the strengths of our study is the use of three 24-h dietary recalls, which offers information on intake from individual foods, being more precise than Food Frequency Questionnaires, which include mostly food groups [48,49]. Additionally, to our knowledge, this is the first study that reports detailed FA intake and evaluates the effect of the AHA dietary counselling among MetS patients. Long-term management of MetS by consumption of a healthy dietary pattern plays an important role in improving health and quality-of-life outcomes. At the same time, we are looking in detail at changes in SFA and TFA in different meal types, meal location, and day of the week, which is an additional strength of our study.

Several limitations should also be considered in light of these results. First, there was no control group without AHA dietary counselling in this investigation, which limited the interpretation of the results. Second, our study was based on the 2006 AHA guidelines, which did not include replacing SFA with PUFA as recommended in the present AHA guidelines. Third, not all SFA generate the same effects. For example, stearic acid has a neutral effect on total cholesterol (TC), LDL-C, and HDL-C, whereas lauric, myristic, and palmitic acids increase TC, LDL-C, and HDL-C, with myristic acid having the most potent hypercholesterolemic effect [50-52]; the type of saturated fat found in dairy products may be protective for chronic disease [53-56]. However, we only calculated the data for total SFA intake, and analyzed the change of total SFA. We decided to focus on the effect of AHA diet on total SFA intake in this manuscript as this is the current dietary recommendation, thus, further research is needed. Lastly, our findings were obtained from obese adults with MetS (BMI between 30 and $40 \mathrm{~kg} / \mathrm{m}^{2}$ ) and the sample size is limited, and therefore it is inadequate for generalization to other populations in the United States.

In conclusion, the one-year AHA dietary counselling increased the proportion of participants complying with the AHA guidelines for dietary intake of total fat, TFA and most prominently SFA, which increased eightfold. However, there is still room for considerable improvement, particularly in levels of SFA intake. Actions that further encourage low-SFA and low-TFA food preparation at home, and strong public health policies that decrease SFA and TFA in restaurants and prepared foods are needed.

Author Contributions: Y.M. designed the study; M.Z. conducted the analyses and wrote the draft of initial manuscript; Y.M., D.C., B.O., B.X., Y.L., L.J.M. and A.M.-C. were involved in revising the manuscript. All authors contributed to interpretation of the data and preparation of the manuscript.

Funding: This research was supported by grant 5R01HL094575-04 to Yunsheng Ma from the National Heart, Lung, and Blood Institute (NHLBI), and in part by the China Scholarship Council (No. 201706260192) to Miaomiao Zhao as a visiting scholar to UMMS.

Acknowledgments: We thank all participants for their dedication to the study.

Conflicts of Interest: The authors declare no conflict of interest.

\section{References}

1. Angell, S.Y.; Cobb, L.K.; Curtis, C.J.; Konty, K.J.; Silver, L.D. Change in trans fatty acid content of fast food purchases associated with New York City's restaurant regulation: A pre-post study. Ann. Intern. Med. 2012, 157, 81-86. [CrossRef] [PubMed]

2. Ruiz-Núñez, B.; Dijck-Brouwer, D.A.; Muskiet, F.A. The relation of saturated fatty acids with low-grade inflammation and cardiovascular disease. J. Nutr. Biochem. 2016, 36, 1-20. [CrossRef] [PubMed]

3. De Souza, R.J.; Mente, A.; Maroleanu, A.; Cozma, A.I.; Ha, V.; Kishibe, T.; Uleryk, E.; Budylowski, P.; Schünemann, H.; Beyene, J.; et al. Intake of saturated and trans unsaturated fatty acids and risk ofall cause mortality, cardiovascular disease, and type 2 diabetes: Systematic review and meta-analysis of observational studies. BMJ 2015, 351, h3978. [CrossRef] [PubMed]

4. Nishida, C.; Uauy, R. WHO Scientific Update on health consequences of trans fatty acids: Introduction. Eur. J. Clin. Nutr. 2009, 63, S1. [CrossRef] [PubMed]

5. Mozaffarian, D.; Stampfer, M.J. Removing industrial trans fat from foods. BMJ 2010, 340, c1826. [CrossRef] [PubMed] 
6. Mozaffarian, D.; Micha, R.; Wallace, S. Effects on coronary heart disease of increasing polyunsaturated fat in place of saturated fat: A systematic review and meta-analysis of randomized controlled trials. PLoS Med. 2010, 7, e1000252. [CrossRef] [PubMed]

7. Hooper, L.; Martin, N.; Abdelhamid, A.; Davey Smith, G. Reduction in saturated fat intake for cardiovascular disease. Cochrane Database Syst. Rev. 2015, 6, CD011737. [CrossRef] [PubMed]

8. Bjermo, H.; Iggman, D.; Kullberg, J.; Dahlman, I.; Johansson, L.; Persson, L.; Berglund, J.; Pulkki, K.; Basu, S.; Uusitupa, M.; et al. Effects of n-6 PUFAs compared with SFAs on liver fat, lipoproteins, and inflammation in abdominal obesity: A randomized controlled trial. Am. J. Clin. Nutr. 2012, 95, 1003-1012. [CrossRef] [PubMed]

9. Farvid, M.S.; Ding, M.; Pan, A.; Sun, Q.; Chiuve, S.E.; Steffen, L.M.; Willett, W.C.; Hu, F.B. Dietary linoleic acid and risk of coronary heart disease: A systematic review and meta-analysis of prospective cohort studies. Circulation 2014, 130, 1568-1578. [CrossRef] [PubMed]

10. Guasch-Ferré, M.; Babio, N.; Martínez-González, M.A.; Corella, D.; Ros, E.; Martín-Peláez, S.; Estruch, R.; Arós, F.; Gómez-Gracia, E.; Fiol, M.; et al. PREDIMED Study Investigators Dietary fat intake and risk of cardiovascular disease and all-cause mortality in a population at high risk of cardiovascular disease. Am. J. Clin. Nutr. 2015, 102, 1563-1573. [CrossRef] [PubMed]

11. Li, Y.; Hruby, A.; Bernstein, A.M.; Ley, S.H.; Wang, D.D.; Chiuve, S.E.; Sampson, L.; Rexrode, K.M.; Rimm, E.B.; Willett, W.C.; et al. Saturated fats compared with unsaturated fats and sources of carbohydrates in relation to risk of coronary heart disease: A prospective cohort study. J. Am. Coll. Cardiol. 2015, 66, 1538-1548. [CrossRef] [PubMed]

12. Jakobsen, M.U.; O’Reilly, E.J.; Heitmann, B.L.; Pereira, M.A.; Bälter, K.; Fraser, G.E.; Goldbourt, U.; Hallmans, G.; Knekt, P.; Liu, S.; et al. Major types of dietary fat and risk of coronary heart disease: A pooled analysis of 11 cohort studies. Am. J. Clin. Nutr. 2009, 89, 1425-1432. [CrossRef] [PubMed]

13. Eckel, R.H.; Jakicic, J.M.; Ard, J.D.; de Jesus, J.M.; Houston-Miller, N.; Hubbard, V.S.; Lee, I.M.; Lichtenstein, A.H.; Loria, C.M.; Millen, B.E.; et al. 2013 AHA/ACC guideline on lifestyle management to reduce cardiovascular risk: A report of the American College of Cardiology / American Heart Association Task Force on Practice Guidelines. Circulation 2014, 129, S76-S99. [CrossRef] [PubMed]

14. Dietary Guidelines Advisory Committee. Scientific Report of the 2015 Dietary Guidelines Advisory Committee. Available online: https://www.health.gov/dietaryguidelines/2015-scientific-report/ (accessed on 15 February 2015).

15. Jacobson, T.A.; Maki, K.C.; Orringer, C.E.; Jones, P.H.; Kris-Etherton, P.; Sikand, G.; La Forge, R.; Daniels, S.R.; Wilson, D.P.; Morris, P.B.; et al. National Lipid Association Recommendations for Patient Centered Management of Dyslipidemia: Part 2. J. Clin. Lipidol. 2015, 9, S1-S22. [CrossRef] [PubMed]

16. Rehm, C.D.; Peñalvo, J.L.; Afshin, A.; Mozaffarian, D. Dietary intake among US adults, 1999-2012. JAMA 2016, 315, 2542-2553. [CrossRef] [PubMed]

17. Chen, L.Y.; Qiao, Q.H.; Zhang, S.C.; Chen, Y.H.; Chao, G.Q.; Fang, L.Z. Metabolic syndrome and gallstone disease. World J. Gastroenterol. 2012, 18, 4215-4220. [CrossRef] [PubMed]

18. Gill, R.M.; Khan, S.A.; Jackson, R.T.; Duane, M. Prevalence of the Metabolic Syndrome in Central and South American Immigrant Residents of the Washington, DC, Area. J. Nutr. Metab. 2017, 2017, 9531964. [CrossRef] [PubMed]

19. Lovre, D.; Mauvais-Jarvis, F. Trends in Prevalence of the Metabolic Syndrome. JAMA 2015, $314,950$. [CrossRef] [PubMed]

20. Khalfa, A.; Tiali, A.; Zemour, L.; Fatah, A.; Mekki, K. Prevalence of metabolic syndrome and its association with lifestyle and cardiovascular biomarkers among postmenopausal women in western Algeria. Int. J. Gynaecol. Obstet. 2017, 138, 201-206. [CrossRef] [PubMed]

21. Nupponen, M.; Pahkala, K.; Juonala, M.; Magnussen, C.G.; Niinikoski, H.; Rönnemaa, T.; Viikari, J.S.; Saarinen, M.; Lagström, H.; Jula, A.; et al. Metabolic syndrome from adolescence to early adulthood: Effect of infancy-onset dietary counseling of low saturated fat: The Special Turku Coronary Risk Factor Intervention Project (STRIP). Circulation 2015, 131, 605-613. [CrossRef] [PubMed]

22. Micha, R.; Mozaffarian, D. Trans fatty acids: Effects on metabolic syndrome, heart disease and diabetes. Nat. Rev. Endocrinol. 2009, 5, 335-344. [CrossRef] [PubMed] 
23. Nettleton, J.A.; Jebb, S.; Risérus, U.; Koletzko, B.; Fleming, J. Role of dietary fats in the prevention and treatment of the metabolic syndrome. Ann. Nutr. Metab. 2014, 64, 167-178. [CrossRef] [PubMed]

24. Wang, J.; Olendzki, B.C.; Wedick, N.M.; Persuitte, G.M.; Culver, A.L.; Li, W.; Merriam, P.A.; Carmody, J.; Fang, H.; Zhang, Z.; et al. Challenges in sodium intake reduction and meal consumption patterns among participants with metabolic syndrome in a dietary trial. Nutr. J. 2013, 12, 163. [CrossRef] [PubMed]

25. Grundy, S.M.; Cleeman, J.I.; Daniels, S.R.; Donato, K.A.; Eckel, R.H.; Franklin, B.A.; Gordon, D.J.; Krauss, R.M.; Savage, P.J.; Smith, S.C.; et al. Diagnosis and management of the metabolic syndrome: An American Heart Association/National Heart, Lung, and Blood Institute Scientific Statement. Circulation 2005, 112, 2735-2752. [CrossRef] [PubMed]

26. American Heart Association Nutrition Committee; Lichtenstein, A.H.; Appel, L.J.; Brands, M.; Carnethon, M.; Daniels, S.; Franch, H.A.; Franklin, B.; Kris-Etherton, P.; Harris, W.S.; et al. Diet and lifestyle recommendations revision 2006: A scientific statement from the American Heart Association Nutrition Committee. Circulation 2006, 114, 82-96. [CrossRef] [PubMed]

27. Ma, Y.; Olendzki, B.C.; Wang, J.; Persuitte, G.M.; Li, W.; Fang, H.; Merriam, P.A.; Wedick, N.M.; Ockene, I.S.; Culver, A.L.; et al. Single-component versus multicomponent dietary goals for the metabolic syndrome: A randomized trial. Ann. Intern. Med. 2015, 162, 248-257. [CrossRef] [PubMed]

28. Schakel, S.F. Maintaining a nutrient database in a changing marketplace: Keeping pace with changing food products-a research perspective. J. Food Comp. Anal. 2001, 14, 315-322. [CrossRef]

29. Corwin, R.L.; Hartman, T.J.; Maczuga, S.A.; Graubard, B.I. Dietary saturated fat intake is inversely associated with bone density in humans: Analysis of NHANES III. J. Nutr. 2006, 136, 159-165. [CrossRef] [PubMed]

30. Boyd, N.F.; Stone, J.; Vogt, K.N.; Connelly, B.S.; Martin, L.J.; Minkin, S. Dietary fat and breast cancer risk revisited: A meta-analysis of the published literature. Br. J. Cancer 2003, 89, 1672-1685. [CrossRef] [PubMed]

31. Lof, M.; Weiderpass, E. Impact of diet on breast cancer risk. Curr. Opin. Obstet. Gynecol. 2009, 21, 80-85. [CrossRef] [PubMed]

32. Lin, O.S. Acquired risk factors for colorectal cancer. Methods Mol. Biol. 2009, 472, 361-372. [CrossRef] [PubMed]

33. Crowe, F.L.; Allen, N.E.; Appleby, P.N.; Overvad, K.; Aardestrup, I.V.; Johnsen, N.F.; Tjønneland, A.; Linseisen, J.; Kaaks, R.; Boeing, H.; et al. Fatty acid composition of plasma phospholipids and risk of prostate cancer in a case-control analysis nested within the European Prospective Investigation into Cancer and Nutrition. Am. J. Clin. Nutr. 2008, 88, 1353-1363. [CrossRef] [PubMed]

34. Kurahashi, N.; Inoue, M.; Iwasaki, M.; Sasazuki, S.; Tsugane, A.S. Japan Public Health Center-Based Prospective Study Group. Dairy product, saturated fatty acid, and calcium intake and prostate cancer in a prospective cohort of Japanese men. Cancer Epidemiol. Biomark. Prev. 2008, 17, 930-937. [CrossRef] [PubMed]

35. Pérez-Farinós, N.; Dal Re Saavedra, M.Á.; Villar Villalba, C.; Robledo de Dios, T. Trans-fatty acid content of food products in Spain in 2015. Gac. Sanit. 2016, 30, 379-382. [CrossRef] [PubMed]

36. US Food and Drug Administration. Revealing Trans Fats. Available online: https://www.highbeam.com/ doc/1G1-109906683.html (accessed on 1 September 2003).

37. Rubinstein, A.; Elorriaga, N.; Garay, O.U.; Poggio, R.; Caporale, J.; Matta, M.G.; Augustovski, F.; Pichon-Riviere, A.; Mozaffarian, D. Eliminating artificial trans fatty acids in Argentina: Estimated effects on the burden of coronary heart disease and costs. Bull. World Health Organ. 2015, 93, 614-622. [CrossRef] [PubMed]

38. Allen, K. Partially Hydrogenated Oils and Trans Fats Information for Consumers. Available online: https:/ / digitalcommons.usu.edu/extension_curall/749 (accessed on 18 June 2015).

39. US Food and Drug Administration. Final Determination Regarding Partially Hydrogenated Oils (Removing Trans Fat). Available online: https://www.fda.gov/food/ingredientspackaginglabeling/ foodadditivesingredients/ucm449162.htm (accessed on 18 May 2018).

40. Tortosa-Caparrós, E.; Navas-Carrillo, D.; Marín, F.; Orenes-Piñero, E. Anti-inflammatory effects of omega 3 and omega 6 polyunsaturated fatty acids in cardiovascular disease and metabolic syndrome. Crit. Rev. Food Sci. Nutr. 2017, 57, 3421-3429. [CrossRef] [PubMed]

41. Balk, E.M.; Lichtenstein, A.H. Omega-3 Fatty Acids and Cardiovascular Disease: Summary of the 2016 Agency of Healthcare Research and Quality Evidence Review. Nutrients 2017, 9, 865. [CrossRef] [PubMed] 
42. Tørris, C.; Småstuen, M.C.; Molin, M. Nutrients in Fish and Possible Associations with Cardiovascular Disease Risk Factors in Metabolic Syndrome. Nutrients 2018, 10, 952. [CrossRef] [PubMed]

43. Gillingham, L.G.; Harris-Janz, S.; Jones, P.J. Dietary monounsaturated fatty acids are protective against metabolic syndrome and cardiovascular disease risk factors. Lipids 2011, 46, 209-228. [CrossRef] [PubMed]

44. Ros, E. Dietary cis-monounsaturated fatty acids and metabolic control in type 2 diabetes. Am. J. Clin. Nutr. 2003, 78, 617S-625S. [CrossRef] [PubMed]

45. Kris-Etherton, P.M. AHA Science Advisory. Monounsaturated fatty acids and risk of cardiovascular disease. Circulation 1999, 100, 1253-1258. [CrossRef] [PubMed]

46. Mente, A.; de Koning, L.; Shannon, H.S.; Anand, S.S. A systematic review of the evidence supporting a causal link between dietary factors and coronary heart disease. Arch. Intern. Med. 2009, 169, 659-669. [CrossRef] [PubMed]

47. Sacks, F.M.; Lichtenstein, A.H.; Wu, J.H.Y.; Appel, L.J.; Creager, M.A.; Kris-Etherton, P.M.; Miller, M.; Rimm, E.B.; Rudel, L.L.; Robinson, J.G.; et al. Dietary Fats and Cardiovascular Disease: A Presidential Advisory from the American Heart Association. Circulation 2017, 136, e1-e23. [CrossRef] [PubMed]

48. Olendzki, B.; Procter-Gray, E.; Magee, M.F.; Youssef, G.; Kane, K.; Churchill, L.; Ockene, J.; Li, W. Racial Differences in Misclassification of Healthy Eating Based on Food Frequency Questionnaire and 24 Hour Dietary Recalls. J. Nutr. Health Aging 2017, 21, 787-798. [CrossRef] [PubMed]

49. Micha, R.; Mozaffarian, D. Saturated fat and cardiometabolic risk factors, coronary heart disease, stroke, and diabetes: A fresh look at the evidence. Lipids 2010, 45, 893-905. [CrossRef] [PubMed]

50. Natarajan, L.; Pu, M.; Messer, K. Exact statistical tests for the intersection of independent lists of genes. Ann. Appl. Stat. 2012, 6, 521-541. [CrossRef] [PubMed]

51. Hunter, J.E.; Zhang, J.; Kris-Etherton, P.M. Cardiovascular disease risk of dietary stearic acid compared with trans, other saturated, and unsaturated fatty acids: A systematic review. Am. J. Clin. Nutr. 2010, 91, 46-63. [CrossRef] [PubMed]

52. Flock, M.R.; Kris-Etherton, P.M. Diverse physiological effects of long-chain saturated fatty acids: Implications for cardiovascular disease. Curr. Opin. Clin. Nutr. Metab. Care 2013, 16, 133-140. [CrossRef] [PubMed]

53. Warensjö, E.; Jansson, J.H.; Cederholm, T.; Boman, K.; Eliasson, M.; Hallmans, G.; Johansson, I.; Sjögren, P. Biomarkers of milk fat and the risk of myocardial infarction in men and women: A prospective, matched case-control study. Am. J. Clin. Nutr. 2010, 92, 194-202. [CrossRef] [PubMed]

54. Soedamah-Muthu, S.S.; Ding, E.L.; Al-Delaimy, W.K.; Hu, F.B.; Engberink, M.F.; Willett, W.C.; Geleijnse, J.M. Milk and dairy consumption and incidence of cardiovascular diseases and all-cause mortality: Dose-response meta-analysis of prospective cohort studies. Am. J. Clin. Nutr. 2011, 93, 158-171. [CrossRef] [PubMed]

55. Azadbakht, L.; Mirmiran, P.; Esmaillzadeh, A.; Azizi, F. Dairy consumption is inversely associated with the prevalence of the metabolic syndrome in Tehranian adults. Am. J. Clin. Nutr. 2005, 82, 523-530. [CrossRef] [PubMed]

56. Gibson, R.A.; Makrides, M.; Smithers, L.G.; Voevodin, M.; Sinclair, A.J. The effect of dairy foods on CHD: A systematic review of prospective cohort studies. Br. J. Nutr. 2009, 102, 1267-1275. [CrossRef] [PubMed]

(C) 2018 by the authors. Licensee MDPI, Basel, Switzerland. This article is an open access article distributed under the terms and conditions of the Creative Commons Attribution (CC BY) license (http://creativecommons.org/licenses/by/4.0/). 